\title{
ABSTRACT \\ BEYOND THE FORCE-SUBSTANCE DICHOTOMY: EXAMINING THE EXPERIENCE OF COMBINED AND INCAPACITATED TYPE RAPES AND THEIR RELATION TO PTSD SYMPTOMS
}

\author{
by Amy A. McConnell
}

Prior research has examined how posttraumatic stress disorder (PTSD) is impacted by different rape types, defined by aspects of the assault such as the method of coercion used. Previous research utilizing methodology that classifies rape experiences as either forcible or substance-involved has yielded mixed findings regarding differences between these two rape types in relation to PTSD. More recent evidence supports the idea that there may be at least two additional rape types warranting empirical investigation, including combined rapes in which force and substance-involvement are present in the same incident, and incapacitated rapes in which victims are intoxicated to the point of unconsciousness during the assault. The current study utilized a sample of 161 community emerging adult women to examine the prevalence and relationship to PTSD symptom severity and assault correlates of four different rape types, based on method of coercion: forcible-only, impaired, combined, and incapacitated. Results indicated that combined and incapacitated rapes are experienced by a significant number of rape victims, and that combined rapes are associated with significantly more severe PTSD symptoms than forcible-only and impaired rapes. Furthermore, differences among the groups were found for peritraumatic fear and injury, and acknowledgment. 


\title{
BEYOND THE FORCE-SUBSTANCE DICHOTOMY: EXAMINING THE EXPERIENCE OF COMBINED AND INCAPACITATED TYPE RAPES AND THEIR RELATION TO PTSD SYMPTOMS
}

\author{
A Thesis \\ Submitted to the \\ Faculty of Miami University \\ in partial fulfillment of \\ the requirements for the degree of \\ Master of the Arts \\ by \\ Amy A. McConnell \\ Miami University \\ Oxford, Ohio \\ 2016 \\ Advisor: Terri L. Messman-Moore, Ph.D. \\ Reader: Elise M. Clerkin, Ph.D. \\ Reader: Aaron M. Luebbe, Ph.D.
}

C2016 Amy A. McConnell 
This thesis titled

BEYOND THE FORCE-SUBSTANCE DICHOTOMY: EXAMINING THE EXPERIENCE OF COMBINED AND INCAPACITATED TYPE RAPES AND THEIR RELATION TO PTSD SYMPTOMS

by

Amy A. McConnell

has been approved for publication by

The College of Arts and Science

and

Department of Psychology

Terri L. Messman-Moore, Ph.D.

Elise M. Clerkin, Ph.D.

Aaron M. Luebbe, Ph.D. 


\section{Table of Contents}

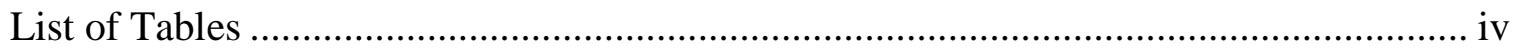

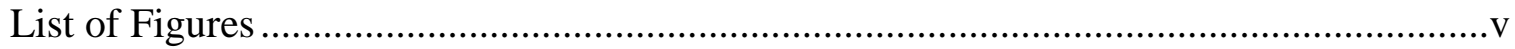

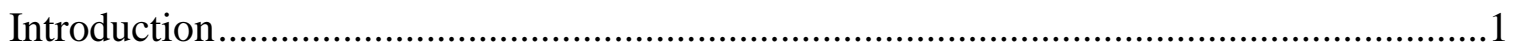

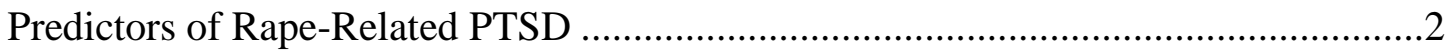

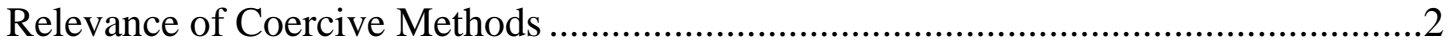

A Non-Dichotomous Conceptualization of Rape ......................................................

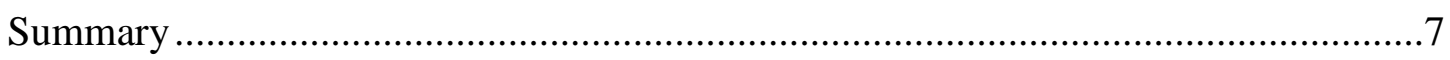

Research Questions and Hypotheses ……………………......................................

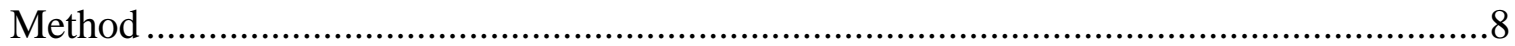

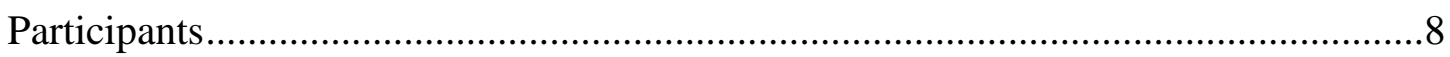

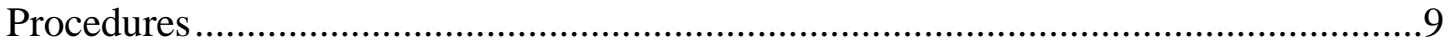

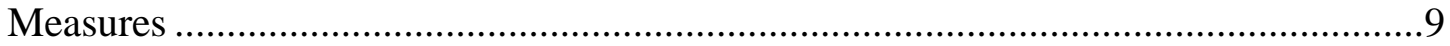

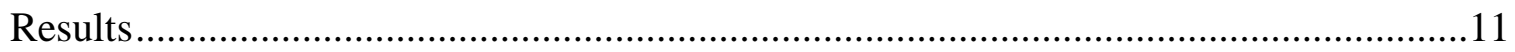

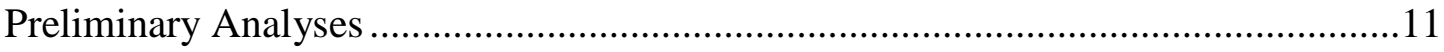

Prevalence of Rape by Method of Coercion ............................................................12

Rape Type and PTSD Symptoms .................................................................12

Assault Characteristics and Consequences .................................................................13

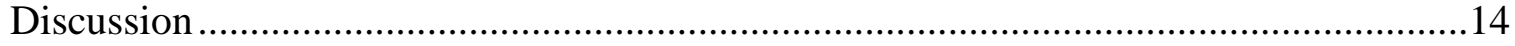

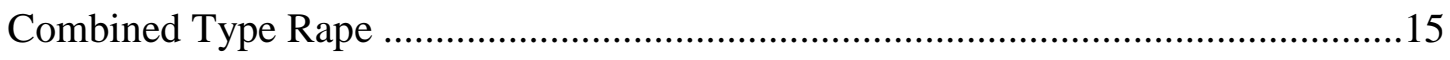

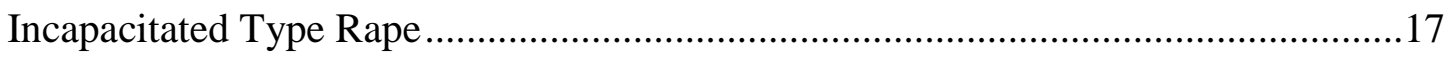

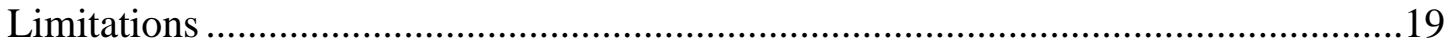

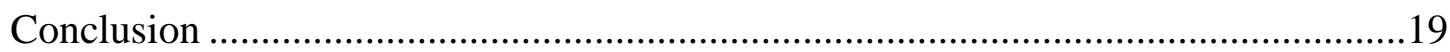

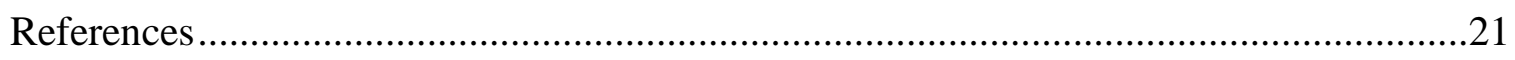

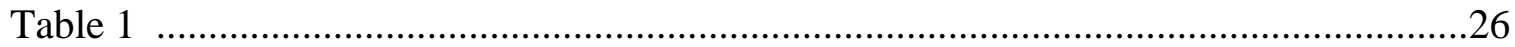

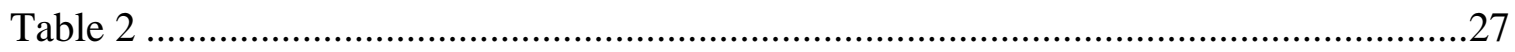

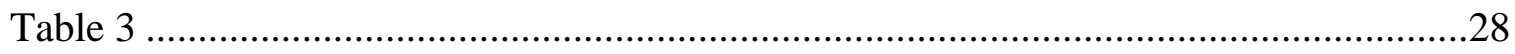

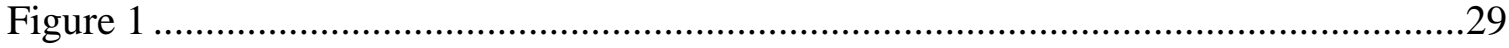

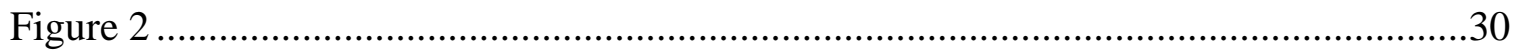

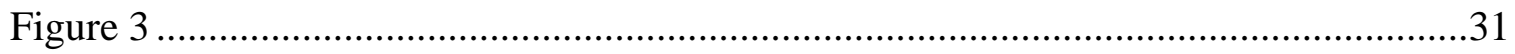




\section{List of Tables}

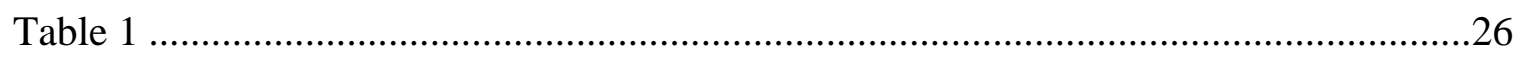

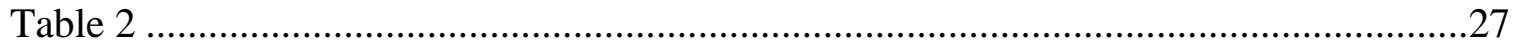

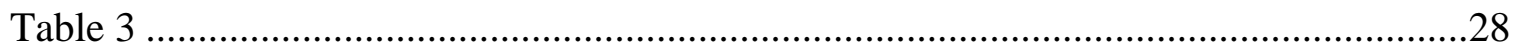




\section{List of Figures}

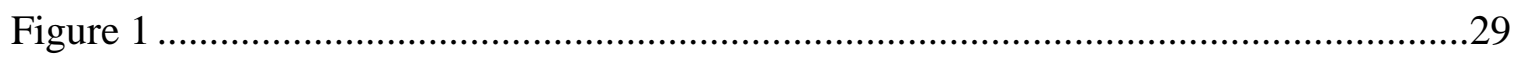

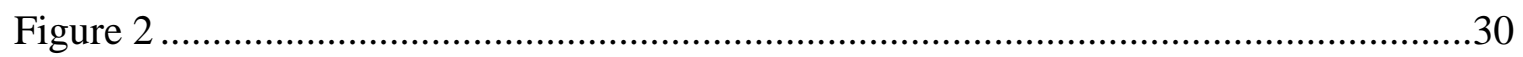

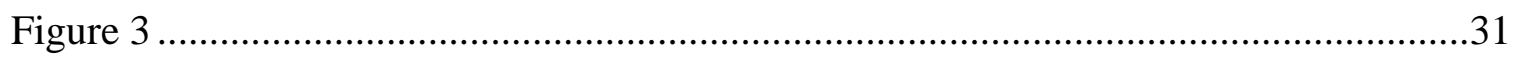




\section{Introduction}

Despite increasing awareness that sexual violence is a pervasive and serious problem, perpetration of rape and sexual assault against women continues to occur at disturbingly high rates. The most recent nationally representative data estimate a lifetime prevalence of rape victimization among women at $19.3 \%$, with an additional $43.9 \%$ of women reporting a lifetime history of sexual violence other than rape (Breiding et al., 2014). Although sexual violence is a serious threat to all women, data from the National Crime Victimization Survey (NCVS; U.S. Department of Justice, 2014) and the National Intimate Partner and Sexual Violence Survey (NISVS; Black et al., 2011; Breiding et al., 2014) have consistently shown that young adult women (ages 18-24) experience the highest rates of both rape and sexual assault compared to any other age group, indicating the need for research focusing on this age group's experience of and recovery from sexual violence.

In addition to its pervasiveness, sexual victimization experiences in adulthood are associated with many negative mental health sequelae, including depression, anxiety, substance abuse, and posttraumatic stress disorder (PTSD), making it an important target for psychological research (Kessler et al., 1995; Kilpatrick \& Acierno, 2003; Resick, 1993). Significantly, the link between sexual victimization and PTSD is exceptionally strong, relative to the relationships between other types of trauma and PTSD. In Kessler and colleagues' (1995) study, rape was the type of trauma most highly associated with PTSD, with nearly $46 \%$ of women who identified rape as their most distressing traumatic event meeting criteria for PTSD, a finding that has been replicated multiple times in the literature (Breslau et al., 1998; Breslau, 2009; Faravelli, Giugni, Salvatori, \& Ricca, 2004; Frans, Rimmö, Åberg, \& Fredrikson, 2005).

Subsequently, much attention has been given to identifying factors that predict PTSD in the aftermath of rape experiences. While a number of strong predictors have emerged from this line of inquiry, rape type (defined by the predominant method of coercion used, either force or substance-involved impairment) has demonstrated inconsistent associations with PTSD. The goal of the proposed study was to clarify these effects by extending research investigating the relationship between rape type and PTSD symptoms. Our primary aim was to investigate whether moving to a more complex system of categorizing substance-involved rape is useful in understanding PTSD symptom severity and presentation among young adult women with experiences of rape. Specifically, we conducted an empirical investigation of two under-studied 
rape types (i.e., combined and incapacitated rape), their relationship to PTSD symptom severity, and their similarities and differences to more commonly researched forcible-only and impaired rape experiences.

\section{Predictors of Rape-related PTSD}

Although the relationship between rape experiences and PTSD is robust, estimates indicate that approximately half of women with rape victimization histories will not meet diagnostic criteria for the disorder. Given this, an abundance of research has investigated what factors predict PTSD following adult rape. This research has revealed three categories of risk factors: 1) pre-trauma vulnerabilities such as prior victimization history (Nishith, Mechanic, \& Resick, 2000), prior mental health difficulties (Acierno, Resnick, Kilpatrick, Saunders, \& Best, 1999), and genetic risk (Stein, Jang, Taylor, Vernon, \& Livesley, 2002); 2) post-trauma experiences such as negative social reactions (Ullman, Filipas, Townsend, \& Starzynski, 2007), acknowledging the event as a sexual assault or rape (Layman, Gidycz, \& Lynn, 1996), and selfblame (Ullman et al., 2007); and 3) peritraumatic experiences such as fear experienced during the assault (Brewin, Andrews, \& Rose, 2000), severity of injury associated with the assault (Bownes, O’Gorman, \& Sayers, 1991), and the method of coercion used (Brown, Testa, \& Messman-Moore, 2009). The present study focuses on one component of the latter category: method of coercion.

\section{Relevance of Coercive Methods}

For much of the history of sexual assault research and legal policy, rape was operationally defined as nonconsensual sexual penetration occurring due to the threat, or actual use of force by the perpetrator. Only in the past decade have sexual assault researchers begun to consistently account for the presence of alcohol or other substances during the assault when examining the impact of rape on mental health, a trend mirrored in legal definitions of rape as well. Indeed, as recently as 2012 the FBI's Uniform Crime Report did not recognize experiences in which physical force was not present, as in the case of some substance-involved rapes (U.S. Department of Justice, 2012). Changes to both research and legal conceptualizations of rape did not begin to take place until relatively recently, despite longstanding evidence that approximately half of sexual assaults are somehow alcohol-involved (Abbey, Zawacki, Buck, Clinton, \& McAuslan, 2004). In recent years, researchers and legal statutes alike have expanded the definition of rape and sexual assault to include cases in which alcohol or drugs, ingested either 
voluntarily or involuntarily, prevent the victim from providing consent. Due to the field's growing recognition of the existence of substance-involved rape, a methodological trend in recent studies has been to classify rape experiences as either forcible or substance-involved and to examine whether the two types of rape experiences differ on assault characteristics and consequences that are known to predict PTSD, as well as the risk for PTSD and the severity of reported PTSD symptoms (Griffin \& Read, 2012; Krebs, Lindquist, Warner, Fisher, \& Martin, 2009; Lawyer, Resnick, Bakanic, Burkett, \& Kilpatrick, 2010; Mohler-Kuo, Dowdall, Koss, \& Weschler, 2004; Ullman \& Najdowski, 2010). These substance-involved experiences have been referred to in the literature by a number of names, including drug/alcohol-facilitated rape, drug/alcohol-involved rape, impaired rape, and incapacitated rape. For the purposes of this paper, these experiences will be broadly referred to as substance-involved rape. Further, when possible, these experiences will be broken down into typologies (i.e., combined, impaired, and incapacitated type rape) using the researchers' terms, recognizing that these definitions are not consistent across studies.

Differences in rape characteristics and consequences. In one early study examining how the actual rape experience might differ based on coercive tactic (i.e., physical force versus intoxication), Abbey and colleagues (2004) found, unsurprisingly, that forcible rapes were characterized by greater verbal and physical resistance from the victim, and resulted in more injury than substance-involved assaults. However, it is unclear whether differences in rape characteristics are actually a difference of kind (i.e., the types of characteristics and consequences associated with each rape type are different) rather than a difference of degree (i.e., the types of characteristics and consequences associated with each rape type are the same, but vary in their strength of association). A more recent study showed that, whereas forcible rape was positively correlated with fear, force, recall of the event, and labeling the assault as a rape, these same variables were negatively associated with substance-involved rape (Zinzow et al., 2010). Given prior research indicating that injury, fear, force, and labeling are predictive of PTSD symptoms (Bownes et al., 1991; Brewin et al., 2000; Layman et al., 1996), it might be expected that the comparatively stronger associations of these factors with forcible rape would predict elevated PTSD symptoms among women with this type of rape experience, compared to those reporting a substance-involved rape. However, other research shows that post-assault consequences typically associated with PTSD symptoms, such as self-blame and negative social 
reactions to disclosure, are higher among substance-involved rapes compared to forcible rapes (Ullman \& Najdowski, 2010). Given that different types of rape are associated with different correlates of PTSD, it follows that the method of coercion or other aspects of the rape experience may be associated with a relatively unique pattern of PTSD symptoms or PTSD severity. Although both forcible and substance-involved forms of assault are associated with correlates of PTSD (e.g., injury in the case of forcible assault, self-blame in the case of substance-involved assault), the question remains whether patterns of association with PTSD would vary by type of assault. This question will be explored further below.

PTSD symptom severity. Research studies that have categorized rape experiences as either forcible or substance-involved have yielded mixed findings concerning the relationship between coercive method and PTSD. Among college women, those with experiences of forcible rape reported more posttraumatic stress symptoms than those with substance-involved experiences (Brown et al., 2009). However, within a slightly older, community sample of women there were no significant differences in posttraumatic stress symptoms between women with a history of forcible rape versus substance-involved rape (Brown et al., 2009). The picture is further complicated by evidence that the relationship between assault type and PTSD symptoms may vary based on symptom cluster. In another study of non-college-age community women, Kaysen et al. (2010) examined differences in each PTSD symptom cluster over time between women with histories of either substance-involved physical or sexual assault or forcible physical or sexual assault. The results showed that initially, women who did not experience substanceinvolved assault had higher re-experiencing symptoms than did women who experienced substance-involved assaults. However, there were no differences on avoidance or hyperarousal symptoms, and the substance-involved group's symptoms were more chronic than the comparison group (Kaysen et al., 2010). While these conflicting findings may be due to differences in the samples (i.e., college vs. community), recent emerging evidence suggests that important qualitative distinctions in rape experiences may be lost when categorizing incidents as either forcible or substance-involved. Though only a few studies thus far have moved beyond this dichotomy, the findings have important implications for future research.

\section{A Non-Dichotomous Conceptualization of Rape}

As mentioned earlier, the majority of research on rape either does not take into account the type of coercion used (examines all types of rape together) or uses a dichotomous approach, 
distinguishing forcible from substance-involved rapes. However, this approach does not account for the heterogeneity of substance-involved rape experiences, which are complex. Some cases of substance-involved rape may concurrently involve physical force (referred to for the purposes of this paper as a combined type rape). Other incidents may occur in the presence of significant levels of intoxication which impact the victim's ability to provide consent (i.e., impaired type rape); and still other incidents may involve such high degrees of intoxication as to render the victim unconscious during all or part of the assault (i.e., incapacitated type rape). Though research recognizing this complexity is currently quite limited, recent evidence supports a more complex conceptualization of substance-involved rape.

Combined type rape. Researchers have rarely addressed the overlap between force and substance-involvement when classifying rapes by method of coercion. Force and substances are not mutually exclusive; they can be present in the same incident. Typically, studies tackle this issue in one of two ways. One way is to create non-mutually exclusive groups (i.e., rapes characterized by both force and substance-involvement are placed in both the forcible and substance-involved groups; Walsh et al., 2013; Zinzow et al., 2010). A second, more common method largely disregards the overlap, treating them in a mutually exclusive or dichotomous manner (i.e., rapes are classified as either forcible or substance-involved, based on a researcherdefined coding hierarchy; Griffin \& Read, 2012; Krebs et al., 2009; Lawyer et al., 2010; MohlerKuo et al., 2004; Ullman \& Najdowski, 2010). While efficient and parsimonious methods, it is possible that these approaches do not adequately capture the heterogeneous nature of substanceinvolved rapes. In contrast to these approaches, recent research has examined whether rape experiences characterized by both force and substance-involvement are associated with different outcomes than forcible-only or impaired rapes.

In the first study to our knowledge that examined combined type rape, Zinzow and colleagues (2012) focused on four groups of women based upon type of coercion: forcible-only, impaired, combined, and a group of women who had not experienced adult rape. In that study, women with a history of combined type rape reported the highest rates of both lifetime (52\%) and current PTSD diagnosis (43\%), compared to women with forcible-only or impaired rape experiences. The combined type rape group also had the highest rates of comorbid diagnoses (i.e., MDE, alcohol or drug abuse), indicating a generally greater propensity for negative mental health consequences compared to other groups. The prevalence of lifetime PTSD was fairly 
equivalent for the forcible-only (34\%) and impaired rape groups (30\%). While this study was the first to explicitly include combined type rapes, several important questions were left unanswered. The study did not examine whether there were differences in the severity of PTSD symptoms, or whether the relationship of rape type to PTSD was uniform across symptom clusters. Furthermore, the study did not examine whether characteristics of the assault differed for the combined type group compared to the more prototypical forcible-only and impaired assaults. Although only one study to our knowledge has investigated combined type rape, the findings support the validity of its existence as a phenomenon worthy of empirical attention. Zinzow and colleagues (2012) found evidence for a strong relationship between combined type rape and PTSD. However, it remains the only study to date to examine this group explicitly; thus, further research is needed not only to replicate Zinzow and colleagues' findings, but to extend this research to examine whether these differences exist in terms of symptom severity as well.

Incapacitated rape. There is almost no research that focuses on the distinction between substance-involved rapes in which the victim remained conscious and those in which the victim was unconscious. Based upon current methodology, individuals who are unconscious may be labeled as incapacitated, whereas those who are intoxicated but not incapacitated may be labeled as impaired (Littleton, Grills-Taquechel, \& Axsom, 2009). In one study of college women, Littleton and colleagues (2009) found that $21 \%$ of rape victims were incapacitated, whereas $41 \%$ were intoxicated but conscious (i.e., were impaired). However, to our knowledge no other studies have made this distinction.

It may be important to distinguish between impaired and incapacitated rape when examining outcomes. Based upon current conceptualizations of the development of PTSD, there is theoretical reason to suggest that differences between these groups may exist. Both Brewin's (1996) dual representation theory of PTSD and Ehlers and Clark's (2000) cognitive theory of PTSD propose that faulty encoding of the traumatic memory leads to the intrusive symptoms (i.e., flashbacks) at the core of PTSD. However, high levels of intoxication have been associated with deficits in hippocampal functions necessary to memory formation (White, 2003), and neurological research has found that loss of consciousness during a traumatic event is associated with lower likelihood of PTSD diagnosis and frequency of intrusive memories (Glaesser, Neuner, Lutgehetmann, Schmidt, \& Elbert, 2004). Thus, rapes in which the victim is incapacitated due to high doses of alcohol or drugs may be characterized by diminished memory 
encoding, which in turn may indicate that lower levels of PTSD symptoms (particularly intrusive symptoms) would be expected among this group.

Only one study to our knowledge has distinguished between impaired and incapacitated victims. Contrary to the expectations outlined above, Littleton and colleagues (2009) found no difference in PTSD symptoms between women who were not intoxicated, women who were impaired, and women who were incapacitated during the assault. Although Littleton and colleagues (2009) did not find differences between the incapacitated and the impaired rape victims on overall levels of PTSD, they did not test for differences on specific PTSD clusters, which may be especially important for this type of rape experience given the links between consciousness, memory formation, and PTSD. Due to the limited knowledge in this area, further research is needed to determine whether incapacitated type rapes differ (as would be theoretically implicated) from other substance-involved groups, including impaired and combined type groups.

\section{Summary}

The majority of research investigating the relationship between rape type and PTSD symptoms has operated from a dichotomous perspective on rape type. This research has resulted in mixed findings, potentially indicating that a more complex conceptualization of rape type is needed. Furthermore, only a fraction of this research has focused on young adult women specifically, despite the fact that this age group is at the highest risk for sexual assault and rape. Emerging evidence supports the idea that there may be at least two additional "types" of substance-involved rape, including combined type rapes in which force and substanceinvolvement are present in the same incident, and incapacitated type rapes in which victims are intoxicated to the point of unconsciousness during the assault. However, this area of inquiry is still new and several questions, including whether these two types of rape differ from purely forcible or substance-involved assaults in terms of their characteristics, their relation to PTSD symptom severity, and the presentation across symptom clusters. The current study sought to address these gaps in the literature.

\section{Research Questions and Hypotheses}

The goal of the present study was to extend research investigating the relationship between rape type and PTSD symptoms. Specifically, our aim was to investigate whether moving to a more complex system of categorizing substance-involved rapes (see Figure 1) is 
useful in understanding PTSD symptom severity and presentation among women with experiences of rape in adulthood. Using a diverse sample of 161 young adult, community women, we sought to answer the following questions: (1) How prevalent are combined and incapacitated type rapes? (2) Are different types of rape differentially associated with PTSD symptom severity, and are the patterns of differences similar across symptom clusters? (3) Do combined and incapacitated type rapes differ from forcible-only or impaired rapes on known predictors of PTSD, including peritraumatic injury, peritraumatic fear, acknowledgment, and self-blame?

We had no hypotheses regarding the first research question, as it is primarily descriptive in nature. For the second research question, we hypothesized that combined type rapes would be associated with significantly more severe PTSD symptoms (regardless of symptom cluster) compared to impaired and incapacitated type rapes, but would not differ from forcible-only rapes. Further, we hypothesized that incapacitated type rapes would be associated with lower intrusive symptoms than forcible-only, impaired, and combined type rapes, but would be associated with equivalent levels of avoidance and hyperarousal symptoms compared to the impaired and forcible-only groups. With regard to the final research question, we hypothesized that forcible-only and combined type rapes would be associated with greater peritraumatic injury, peritraumatic fear, and acknowledgment, compared to impaired and incapacitated type rapes, and that impaired and incapacitated type rapes would be associated with greater self-blame than forcible-only and combined type rapes.

\section{Method}

\section{Participants}

Participants for the current study were 161 community women who reported a completed rape since age 18, drawn from an original sample of 490 women (see Figure 2 for breakdown of sample selection). Women ages $18-25\left(M_{\text {age }}=22.2 ; S D=2.15\right)$ were recruited for a multi-site (sites in Mississippi, Nebraska, and Ohio) study investigating sexual revictimization. Participants were ethnically diverse (69.4\% Caucasian; 28.5\% African American; 4.6\% Asian/Pacific Islander; $2.8 \%$ American Indian; 1.8\% identified as Other) and from predominantly low socioeconomic backgrounds (43.4\% reported an annual household income of less than $\$ 10,000)$. 


\section{Procedures}

All procedures were approved by the participating institutions' Institutional Review Boards. Recruitment for the study took place in four cities in the Southern and Midwestern United States. Participants were recruited via local advertisements and random community sampling. All participants gave written informed consent before completing the study. Data for the current analyses are from the initial wave of data collection, which included diagnostic interviews, in-lab computer tasks, and a battery of online self-report questionnaires. Participants received $\$ 75$ as compensation for their time.

\section{Measures}

Sexual victimization. Experiences of sexual victimization from the age of 18 until entry into the study were assessed using a modified version of the Sexual Experiences Survey (Koss et al., 1987). This version of the SES includes 20 screening questions in which participants were asked to indicate whether they experienced any of several behaviorally-specific unwanted sexual acts (i.e., contact, oral sex, vaginal or anal intercourse, or vaginal or anal penetration by objects). For each type of act, participants were asked whether verbal coercion, abuse of authority, incapacitation, or threat/use of force was used. If participants endorsed any of the items concerning oral sex, intercourse, or penetration by objects, they were asked to complete followup questions about the details of their most distressing unwanted sexual experience. Overall, $65 \%(n=317)$ of the entire sample $(\mathrm{N}=490)$ reported at least one of these acts on the SES, and $88.6 \%(n=281)$ of those women completed the follow-up questions regarding their most distressing unwanted sexual experience.

Participants provided follow-up data on: (1) the types of sexual acts involved in the assault, (2) the number of perpetrators involved, (3) the age of victim and perpetrator at the time of the assault, (4) time elapsed since the assault, (5) nature of the victim-perpetrator relationship, (6) use of alcohol or drugs by both the victim and perpetrator during the assault, (7) methods of coercion used by the perpetrator (Abbey, BeShears, Clinton-Sherrod, \& McAuslan, 2004), (8) methods of resistance used by the victim (Clay-Warner, 2002), and (9) post-assault experiences, including disclosure experiences and reactions, acknowledgment, attributions of responsibility, and beliefs about recovery (Frazier, 2003). Experiences regarding substance-involved coercion included assessment of whether the victim was intoxicated (yes, no, or unsure) and the victim's perceived level of intoxication on a 5-point scale, ranging from 1 (not at all intoxicated), to 5 
(very intoxicated). In addition, levels of consciousness were assessed in a series of questions regarding the victim's method(s) of resistance; in particular, individuals who indicated a 5 on a 1-5 scale to the statement "I was unconscious and unable to resist" were considered incapacitated.

Peritraumatic fear. Peritraumatic fear was assessed with a single item. Participants were presented with a list of peritraumatic emotions, and indicated on a scale from 1 (not at all) to 7 (very) the degree to which they experienced each emotion at the time of the unwanted sexual activity.

Peritraumatic injury. Peritraumatic injury was assessed with a single item. Participants responded to the question, "Were you injured or did you have physical pain after the unwanted activity?" on a scale from 1 (not at all) to 5 (very much).

Self-blame. Self-blame was assessed with a single item. Participants responded to the question, "If you were to assign responsibility for what happened, how much would you say that each of the following was responsible?" on a scale from 1 (not at all) to 5 (very much). Response options included: a failure to communicate, the man, you, his drinking or drug use, your drinking or drug use, peer pressure from his friends for him to engage in sexual activity.

Acknowledgment. Acknowledgment was assessed with a single item. Participants responded to the question, "Which number best describes the extent to which you consider what happened to be rape?" on a scale from 1 (definitely not rape) to 7 (definitely rape).

Experiences were coded as completed rape or as sexual assault by crossing the type of sexual acts involved in the experience with the methods of coercion used by the perpetrator. Assaults in which any type of oral, vaginal, or anal penetration occurred due to intoxication, or threat/use of force were coded as completed rape; all other sexual victimization experiences were coded as sexual assault. For the current study, completed rapes were further broken down into one of four sub-types: (1) incapacitated rape if the participant indicated that they were both intoxicated and "incapacitated and unable to resist" during the assault (2) combined rape if the participant indicated they were intoxicated at the time of the assault (but conscious) and that force or threat of force was used by the perpetrator, (3) impaired rape if the participant indicated they were intoxicated (but conscious) at the time of the assault but no force or threat of force was used by the perpetrator, and (4) forcible-only rape if the participant indicated that force or threat of force was used by the perpetrator and that they were not intoxicated at the time of the assault. 
PTSD symptom severity. Current PTSD symptoms were assessed using the PTSD Checklist-Civilian Version (PCL-C; Weathers, Litz, Herman, Huska, \& Keane, 1994). The PCL-C is a 17-item self-report measure in which participants were asked to indicate on a 5-point Likert-type scale ranging from (1) not at all to (5) extremely how much they were bothered by each symptom during the past month. The PCL-C yields a total symptom severity score and three subscale scores representing the symptom clusters of DSM-IV PTSD: re-experiencing ("repeated, disturbing memories, thoughts, or images of a stressful experience"), avoidance ("avoiding thinking about or talking about a stressful experience or avoiding having feelings related to it"), and hyperarousal ("trouble falling or staying asleep"). Subscales were scored by summing the items for each subscale, with higher scores indicating more severe symptomatology. The PCL-C has demonstrated sound psychometric properties (Blanchard, Jones-Alexander, Buckley, \& Forneris, 1996). The measure showed good reliability in the current sample, yielding Cronbach's alphas of .91, .88, and .89, for the re-experiencing, avoidance, and hyperarousal subscales, respectively, and .95 for the total scale.

\section{Results}

\section{Preliminary Analyses}

Data were initially examined in SPSS version 22 (IBM, 2013) for outliers and normality. Investigation of boxplots indicated the absence of outliers, and values of skew and kurtosis were found to be within normal limits (skew < 3 and kurtosis < 10; Kline, 1998).

Participants who either did not provide data on the victimization screening questions of the SES or who did answer the screening questions but did not provide follow-up data for the most distressing incident could not be definitively classified as either a non-rape victim or into one of the four rape groups and were thus excluded from analyses $(n=38)$. Patterns of missing data among the remaining study variables were examined using a Missing Value Analysis (MVA). Overall, $2.99 \%$ of data were missing. Little's MCAR test was non-significant, indicating that data were consistent with a missing completely at random pattern, $p=.153$. Given this pattern, multiple imputation (MI) was used to approximate missing values for all non-victimization variables. The use of MI is supported in the literature as a less biased method of managing missing data, compared to alternatives such as casewise deletion or mean replacement (Graham, 2009). Demographic characteristics, rape type, time since assault, peritraumatic fear and injury, 
self-blame, acknowledgment, and PTSD symptoms were used to estimate values of missing data in $20 \mathrm{MI}$ models.

The results of bivariate correlations conducted to examine the relationships between potential covariates (i.e., demographic characteristics and time since assault) and study dependent variables are presented in Table 1. Results indicated that age, student status (coded 0 $=$ not a student, $1=$ student), and race (two variables coded $0=$ not White or not Black, $1=$ White or Black) were not significantly associated with any dependent variables. Participant income was significantly correlated with total, re-experiencing, avoidance/numbing, and hyperarousal PTSD symptoms, peritraumatic fear and injury, and acknowledgment. Further, time since assault was significantly and positively correlated with peritraumatic injury. Thus, these variables were included as covariates in relevant analyses.

\section{Prevalence of Rape by Method of Coercion}

Of the full sample $(\mathrm{N}=490), 32.9 \%(\mathrm{n}=161)$ reported a most distressing unwanted sexual experience of completed rape. Of those, $29.8 \%(n=48)$ reported a forcible-only rape; $34.8 \%(n=56)$ reported an impaired rape; $18 \%(n=29)$ reported a combined rape; and $17.4 \%(n$ $=28$ ) reported an incapacitated rape.

\section{Rape Type and PTSD Symptoms}

Overall, $33.3 \%, 28.6 \%, 58.6 \%$, and $32.1 \%$ of the forcible-only, impaired, combined, and incapacitated rape groups, respectively, exceeded a clinical cut-off score of 44 on the PCL-C. An ANCOVA, accounting for income, was conducted to examine whether the four rape groups differed on total PTSD symptom severity. There was a significant main effect of rape type, $F(3$, $156)=4.49, p=.005, \eta^{2}$ partial $=.079$, as well as income, $F(1,156)=6.28, p=.013, \eta^{2}$ partial $=.039$. Bonferroni-adjusted pairwise comparisons were conducted to determine where among the groups differences in PTSD symptom severity were statistically significant. Women in the combined type rape group had significantly higher PCL-C total scores on average than the forcible-only and impaired groups. There were no other statistically significant differences among the groups with regard to total PTSD symptom severity. See Table 2 for means and standard deviations.

To examine the patterns of group differences across PTSD symptom clusters, a MANCOVA, accounting for income, was performed with the three PCL-C subscale scores entered as dependent variables. There was a significant multivariate effect of rape type on PTSD re-experiencing, avoidance/numbing, and hyperarousal symptoms, Pillai's Trace $=.114, F(9$, 
$468)=2.05, p=.033, \eta^{2}$ partial $=.04$, as well as income, Pillai's Trace $=.05, F(3,154)=2.70, p=$ $.048, \eta^{2}$ partial $=.05$. There were also significant univariate effects of rape type on re-experiencing symptoms, $F(3,156)=3.65, p=.014, \eta^{2}$ partial $=.066$; avoidance/numbing symptoms, $F(3,156)=$ $2.71, p=.047, \eta^{2}$ partial $=.049$; and hyperarousal symptoms, $F(3,156)=5.55, p=.001, \eta^{2}$ partial $=$ .096 .

These significant univariate tests were followed up with Bonferroni-adjusted pairwise comparisons to examine the patterns of differences among the groups for each symptom cluster. These comparisons indicated that women in the combined group reported significantly higher levels of re-experiencing and hyperarousal symptoms on average than women in the forcibleonly and impaired groups, as well as higher levels of avoidance/numbing symptoms on average than the impaired group. There were no significant differences between the women in the incapacitated group and women in the forcible-only, impaired, and combined groups in any of the three symptom clusters. See Table 2 for means and standard deviations.

\section{Assault Characteristics and Consequences}

To examine the third research question, differences among the groups on four variables were examined: peritraumatic injury, peritraumatic fear, attributions of self-blame, and acknowledgment of the experience as a rape. Initially, a MANCOVA was conducted to test for these differences; however, Box's test of equality of covariance matrices and the Levene's test for peritraumatic fear were both significant $(p=.002, p<.001$, respectively), indicating that the assumptions of homogeneity of variance and covariance were violated. Thus, two analyses were conducted: a MANCOVA, controlling for income and time since assault, to test for group differences on peritraumatic injury, attributions of self-blame, and acknowledgment of the experience as a rape, and a Kruskal-Wallis ANOVA testing group differences on peritraumatic fear.

There was a significant multivariate effect of rape type on peritraumatic injury, attributions of self-blame, and acknowledgment, Pillai's Trace $=.293, F(9,465)=5.585, p<$ $.001, \eta^{2}$ partial $=.098$. There were significant univariate effects for peritraumatic injury, $F(3,155)=$ $10.742, p<.001, \eta^{2}$ partial $=.172$, and for acknowledgment, $F(3,155)=12.375, p<.001, \eta^{2}$ partial $=$ .193. There was not a significant univariate effect for self-blame, $F(3,155)=1.627, p=.185$, $\eta_{\text {partial }}^{2}=.031$. The significant ANOVAs were followed up with Bonferroni-adjusted pairwise comparisons to examine the patterns of differences among the groups for each dependent 
variable. These comparisons indicated that the forcible-only and combined group reported significantly more peritraumatic injury than the impaired group, and that the combined group also reported more injury than the incapacitated group. In addition, the forcible-only, combined, and incapacitated groups reported higher levels acknowledgment than the impaired group. See Table 3 for means and standard deviations.

Differences among the groups regarding peritraumatic fear were investigated separately using a Kruskal-Wallis test. Visual assessment of boxplots for each group determined that the distributions were not similar for all groups, thus, the distributions for each group rather than the medians were used for interpretation of the test statistic. Peritraumatic fear ratings were significantly different among the groups, $\chi^{2}(3)=43.013, p<.001$. Subsequent pairwise comparisons using Dunn's (1964) procedure with a Bonferroni correction for multiple comparisons revealed that the distribution of the impaired group (mean rank $=49.71$ ) was significantly different than the distributions of the forcible-only group (mean rank $=98.95$ ), the combined group (mean rank $=104.97)$, and the incapacitated group (mean rank $=88.16$ ), indicating that the impaired group tended to report lower ratings of peritraumatic fear than the forcible-only, combined, and incapacitated groups. See Figure 3 for group distributions.

\section{Discussion}

The current study examined differences in PTSD symptom severity between four rape types (defined by perceived perpetrator tactics) among a diverse sample of young adult, community women. Prior research has examined differences between rapes characterized by forceful tactics and those characterized by substance-related impairment, with conflicting results. The current research extended this literature in several ways, primarily by using incident-level data to expand our understanding of rape type beyond the force-substance dichotomy to include rapes characterized by concurrent use of force and substances (i.e., combined type rape), and those characterized by extreme levels of substance-related impairment (i.e., incapacitated type rape). We examined these groups in relation to each PTSD symptom cluster as well as overall PTSD symptom severity in order to better understand outcomes associated with each rape type. Finally, we investigated differences among the groups on known correlates of rape-related PTSD, including peritraumatic fear and injury, acknowledgment, and self-blame attributions. 


\section{Combined Type Rape}

Although a growing body of research distinguishes substance-involved from forcible rapes, only recently have researchers begun to explore the possibility that some assaults may be characterized by both substance-involvement and force, and that these experiences may be qualitatively different than experiences in which only one method of coercion was used. Thus, the first goal of the current research was to investigate the prevalence of such experiences among a sample of women with a history of rape. Among our sample, the prevalence of combined type rape was $18 \%$. This finding is consistent with previous epidemiological research which indicated that among a nationally representative sample of women, $18.1 \%$ of the rape victim sub-sample were categorized as having experienced a combined type rape (Zinzow et al., 2012). The concordance of these two rates, generated using differing measures and samples, lends further support that this type of rape not only exists, but is also experienced by a sizable number of women with experiences of rape, and is thus deserving of continued empirical attention.

Previous research provided preliminary evidence that combined type rapes might be associated with a higher risk for PTSD diagnosis compared to impaired and forcible-only rapes (Zinzow et al., 2012). However, such comparisons between the groups were not statistically tested, nor had differences in symptom severity been examined. Furthermore, even less was known about the characteristics of this understudied type of assault and its consequences. The current study addressed these gaps in the literature by directly testing between-groups differences on PTSD symptom severity within each symptom cluster, as well as differences on peritraumatic fear, peritraumatic injury, acknowledgment, and self-blame attributions. Consistent with both hypotheses and previous literature (Zinzow et al., 2012), results of the current study demonstrated that combined type rapes were associated with more severe re-experiencing, avoidance/numbing, and hyperarousal symptoms than impaired rapes. Also in line with hypotheses and previous literature (Abbey et al., 2004; Zinzow et al., 2012), combined type rapes were associated with greater peritraumatic injury, peritraumatic fear, and acknowledgment relative to impaired rapes, but not forcible-only rapes. Taken together, these results appear to indicate that when both force and substances are present in a sexual assault, women's experiences of peritraumatic fear, injury, and acknowledgment tend to resemble perceptions of women who experienced forcible rape, rather than those with experiences of impaired rape. Peritraumatic fear, injury, and acknowledgement are associated with PTSD (Bownes et al., 1991; 
Brewin et al., 2000; Layman et al., 1996) and were also elevated in the combined group, which may in turn potentially explain the more severe PTSD symptomatology reported by these women. The current research did not specifically test for this possibility; thus, future research could benefit from examining whether these differences in assault characteristics and consequences translate to differences in PTSD symptomatology.

In partial support of our hypotheses, we also found that the combined type group exhibited more severe re-experiencing and hyperarousal symptoms than forcible-only rape, but the two groups were equivalent with regard to avoidance and numbing symptoms, indicating that the effects of combined methods of coercion are not heterogeneous across symptom clusters. To explain similar findings, Zinzow and colleagues (2012) hypothesized that because combined type rapes are likely to be associated with both the elevated levels of peritraumatic fear and injury associated with forcible rapes as well as elevated levels of self-blame common to impaired rapes, they get the "worst" of both worlds, leading to a comparatively higher risk for PTSD. Although this is a plausible explanation, Zinzow and colleagues did not explicitly test this hypothesis. Further, the current study did not find evidence for such an explanation. Instead, combined and forcible-only rapes were associated with equivalent levels of peritraumatic fear, peritraumatic injury, and self-blame, despite differing in the severity of re-experiencing and hyperarousal symptoms. An alternate hypothesis is that alcohol intoxication alters the storage and retrieval of memories in a manner that de-contextualizes them, resulting in more severe intrusive symptoms. Thus, the elevated peritraumatic fear and injury common to both forcible and combined type rapes, in conjunction with the physiological effects of alcohol, may contribute to more severe reexperiencing symptoms.

Recent experimental studies found that low doses of acute alcohol intoxication were associated with increased intrusive memories in response to a trauma video (Bisby et al., 2009; Bisby et al., 2010). Existing research indicates that alcohol interferes with hippocampal functioning, contextual memory, and PTSD symptoms (Acheson, Gresack, \& Risbrough, 2012; Brewin et al., 1996; Brewin, 2001; Söderlund, Grady, Easdon, \& Tulving, 2007; White, 2003). Alcohol negatively impacts hippocampal functioning, with deficits in such processing implicated in the development of PTSD re-experiencing symptoms. The hippocampus plays an important role in contextualizing memory, and it is impairment in this type of memory specifically that is theorized to explain the flashbacks characteristic of PTSD (Brewin et al., 1996; Brewin 2001). 
While it is possible that alcohol's effects on memory may account for the high levels of reexperiencing symptoms among women reporting combined rape, additional research is needed to directly test this explanation, as well as to investigate why the combined type group also exhibited more severe hyperarousal symptoms.

\section{Incapacitated Type Rape}

The extant literature regarding rape types has largely failed to recognize incapacitated type rape as a distinct experience from that of other substance-involved rapes; thus, very little is known about the prevalence and impact of this type of experience. Rather, most previous research in this area trends toward treating all substance-involved rapes (e.g., combined, impaired, and incapacitated types) as homogenous experiences, with incapacitated (i.e., unconscious) type rape typically classified in the same group as impaired (i.e., conscious) type rape. The current research is among the first to parse apart incapacitated from impaired and combined type rapes, and the results offer preliminary support for the continued examination of incapacitated type rape as an experience unique from that of other substance-involved rapes.

Consistent with the only previous study that explicitly examined incapacitated type rape, the prevalence of incapacitated rape among women with an adulthood rape experience in the current sample was $17.4 \%$ (compared to $21 \%$ prevalence reported by Littleton et al., 2009). Though this is only the second study to our knowledge to examine this group, the relative similarity in prevalence between the samples indicates the existence and validity of this type of rape, as experienced by a small but significant proportion of women who experience rape in adulthood. Moreover, almost a third (32.1\%) of this group exceeded a clinical cut-off score for PTSD on the PCL-C, indicating that a substantial proportion of this group would be likely to meet criteria for a diagnosis of DSM-IV PTSD. This is higher than estimates of PTSD among other traumatized populations (Breslau et al., 1998; Kessler et al., 1995).

Incapacitated rapes were most often distinguished from impaired type rapes on relevant assault-related variables that have implications for mental health outcomes, but did not tend to be differentiated from forcible-only or combined type rapes. In particular, the finding that compared to impaired type rapes, incapacitated type rapes were associated with both higher levels of reported peritraumatic fear and with greater acknowledgment of the incident as a rape is interesting in light of the fact that incapacitated type rape is most often not classified separately from impaired type rape in the literature. It will be necessary for future studies to further 
examine whether these differences are replicated and whether there may be additional differences between these two groups. For example, there is growing recognition in the field of traumatic stress that peritraumatic emotional responses other than fear such as disgust, sadness, and anger, are related to PTSD and other mental health outcomes among trauma survivors (Brewin et al., 2000; Hathaway, Boals, \& Banks, 2010; Rizvi, Kaysen, Gutner, Griffin, \& Resick, 2008). Thus, it will be important to understand the relationship of incapacitated type rapes to these emotional experiences.

Furthermore, the presence of elevations in peritraumatic fear and acknowledgment within this group compared to the impaired type rape group point to different targets of intervention. For example, recent research examining the specificity of different peritraumatic emotions to PTSD symptom clusters has shown that peritraumatic fear uniquely predicts avoidance and numbing symptom severity, even when accounting for peritraumatic experiences of anger, disgust, guilt, and shame (Dewey, Schuldberg, \& Madathil, 2014). Given that empirically supported treatments for PTSD directly aim to reduce avoidance of trauma-related stimuli, it may be that clinicians need to distinguish impaired from incapacitated type rapes in assessing the potential for avoidance throughout the treatment process. Conversely, for women with experiences of impaired type rape who may be more ambivalent about the meaning of the assault (i.e., women with lower levels of rape acknowledgment), research suggests that it may be more important for the therapist to spend time in therapy helping the client secure safety if they have remained in contact with the perpetrator and to work on increasing the client's risk perception skills to prevent future assaults (Littleton, Rhatigan, \& Axsom, 2007).

Interestingly, the incapacitated group did not show any differences in PTSD symptom severity relative to the other three rape groups. We hypothesized that incapacitated rape would be associated with less severe re-experiencing symptoms, compared to the other groups, based on research evidence that high levels of alcohol intoxication impairs memory formation, which is implicated theoretically in the development of PTSD re-experiencing symptoms (Brewin, 1996; Ehlers \& Clark, 2000; White, 2003). While this hypothesis was theoretically plausible, it is not entirely unexpected that a group indicating loss of consciousness during the assault would report equivalent levels of symptoms to the groups who were conscious during the assault. The current findings replicate and extend that of Littleton and colleagues (2009), who found no differences in overall PTSD symptom severity by demonstrating that, similarly, there are no differences at the 
symptom cluster level. Furthermore, research with survivors of both mild and severe traumatic brain injury has demonstrated that PTSD symptoms, including re-experiencing symptoms, may develop with loss of consciousness during the event and in the absence of traumatic memory (for a review, see Bryant, 2001). Thus, while it is not entirely surprising that this group exhibited equivalent levels of PTSD symptoms (regardless of symptom cluster) to the other groups, further research should investigate more deeply the role of memory in incapacitated type rapes, and whether other factors are important in the development of PTSD symptoms among this group.

\section{Limitations}

The findings of the current study must be considered within the context of its limitations. Primarily, all data were retrospective in nature, and are therefore subject to memory bias. This may be a particular issue when asking participants to recall traumatic events, for which memory deficits are common. Using prospective methods of data collection in future research may minimize the effects of recall bias. In addition, the assault characteristics and consequences examined in the current study were measured using single-item, Likert-type questions. More indepth assessment of these constructs using well-validated measures may provide a better understanding of these relationships in future research. Finally, while all participants reported both a sexual assault in adulthood and reported on their current PTSD symptoms, the PCL-C was not specifically anchored to the assault on which the current groups were created. Given evidence that many individuals with an experience of trauma have experienced multiple such traumas across their lifespan, further elucidation of the relationship between these rape types and PTSD symptoms may require more specific assessment.

\section{Conclusion}

Although the study's limitations are important to consider when interpreting the current findings, the study contributes valuable knowledge to a sparse literature. It has taken several decades for substance-involved rape to be recognized as a legitimate experience with serious mental health outcomes, and the field has only begun to recognize that just as distinguishing forcible from substance-involved rapes was useful in understanding the sequelae of rape among adult women, it may be helpful to consider that substance-involved rapes themselves are not homogenous experiences. The current study utilized both prior research and psychological theory to identify potential sub-groups of substance-involved rape that may be differentially related to psychological outcomes. Using a diverse, community sample, and in-depth, incident-level 
assessment of the rape experience, the current study adds novel findings to an emerging body of literature that has implications both for future research and for clinical intervention. 


\section{References}

Abbey, A., BeShears, R., Clinton-Sherrod, A.M., \& McAuslan P. (2004). Similarities and differences in women's sexual assault experiences based on tactics used by perpetrator. Psychology of Women Quarterly 28, 323-332.

Abbey, A., Zawacki, T., Buck, P.O., Clinton, A.M., \& McAuslan, P. (2004). Sexual assault and alcohol consumption: What do we know about their relationship and what types of research are still needed? Aggression and Violent Behavior, 9(3), 271-303.

Acheson, D.T., Gresack, J.E., \& Risbrough, V.B. (2012). Hippocampal dysfunction effects on context memory: possible etiology for posttraumatic stress disorder. Neuropharmacology, 62(2), 674-685.

Acierno, R., Resnick, H., Kilpatrick, D. G., Saunders, B., \& Best, C. L. (1999). Risk factors for rape, physical assault, and posttraumatic stress disorder in women: Examination of differential multivariate relationships. Journal of Anxiety Disorders, 13(6), 541-563.

Bisby, J.A., Brewin, C.R., Leitz, J.R., \& Curran, H.V. (2009). Acute effects of alcohol on the development of intrusive memories. Psychopharmacology, 204(4), 655-666.

Bisby, J.A., King, J.A., Brewin, C.R., Burgess, N., \& Curran, H.V. (2010). Acute effects of alcohol on intrusive memory development and viewpoint dependence in spatial memory support a dual representation model. Biological Psychiatry, 68(3), 280-286.

Black, M.C., Basile, K.C., Breiding, M.J., Smith, S.G., Walters, M.L., Merrick, M.T., ...Stevens M.R. (2011). The National Intimate Partner and Sexual violence Survey (NISVS): 2010 Summary Report. Atlanta, GA: National Center for Injury Prevention and Control, Centers for Disease Control and Prevention.

Bownes, I.T., O'Gorman, E.C., \& Sayers, A. (1991). Assault characteristics and posttraumatic stress disorder in rape victims. Acta Psychiatrica Scandinavica, 83(1), 27-30.

Breiding, M.J., Smith, S.G., Basile, K.C., Walters, M.L., Chen, J., \& Merrick, M.T. (2014). Prevalence and characteristics of sexual violence, stalking, and intimate partner violence victimization: National Intimate Partner and Sexual Violence Survey, United States, 2011. Atlanta, GA: National Center for Injury Prevention and Control, Centers for Disease Control and Prevention.

Breslau, N. (2009). The epidemiology of trauma, PTSD, and other posttrauma disorders. Trauma, Violence, \& Abuse, 10(3), 198-210. 
Breslau, N., Kessler, R.C., Chilcoat, H.D., Schultz, L.R., Davis, G.C., \& Andreski, P. (1998). Trauma and posttraumatic stress disorder in the community: The 1996 Detroit Area Survey of Trauma. Archives of General Psychiatry, 55(7), 626-632.

Brewin, C.R. (2001). A cognitive neuroscience account of posttraumatic stress disorder and its treatment. Behaviour Research and Therapy, 39(4), 373-393.

Brewin, C.R., Andrews, B., \& Rose, S. (2000). Fear, helplessness, and horror in posttraumatic stress disorder: Investigating DSM-IV Criterion A2 in victims of violent crime. Journal of Traumatic Stress, 13(3), 499-509.

Brewin, C.R., Dalgleish, T., \& Joseph, S. (1996). A dual representation theory of posttraumatic stress disorder. Psychological Review, 103(4), 670-686.

Brown, A.L., Testa, M., \& Messman-Moore, T.L. (2009). Psychological consequences of sexual victimization resulting from force, incapacitation, or verbal coercion. Violence against Women, 15(8), 898-919. http://doi.org/10.1177/1077801209335491

Bryant, R.A. (2001). Posttraumatic stress disorder and traumatic brain injury: Can they co-exist? Clinical Psychology Review, 21(6), 931-948.

Clay-Warner, J. (2002). Avoiding rape: The effects of protective actions and situational factors on rape outcome. Violence and Victims, 17(6), 691-705.

Dewey, D., Schuldberg, D., \& Madathil, R. (2014). Do peritraumatic emotions differentially predict PTSD symptom clusters? Initial evidence for emotion specificity. Psychological Reports, 115(1), 1-12.

Dunn, O.J. (1964). Multiple comparisons using rank sums. Technometrics, 6(3), 241-252.

Ehlers, A., \& Clark, D.M. (2000). A cognitive model of posttraumatic stress disorder. Behaviour Research and Therapy, 38(4), 319-345. http://doi.org/10.1016/S0005-7967(99)00123-0

Faravelli, C., Giugni, A., Salvatori, S., \& Ricca, V. (2004). Psychopathology after rape. American Journal of Psychiatry, 161(8), 1483-1485.

Frans, Ö., Rimmö, P. A., Åberg, L., \& Fredrikson, M. (2005). Trauma exposure and posttraumatic stress disorder in the general population. Acta Psychiatrica Scandinavica, 111(4), 291-290.

Frazier, P.A. (2003). Perceived control and distress following sexual assault: A longitudinal test of a new model. Journal of Personality and Social Psychology, 84(6), 1257-1269. 
Glaesser, J., Neuner, F., Lütgehetmann, R., Schmidt, R., \& Elbert, T. (2004). Posttraumatic stress disorder in patients with traumatic brain injury. BMC Psychiatry, 4(5).

Graham, J.W. (2009). Missing data analysis: Making it work in the real world. Annual Review of Psychology, 60, 549-576.

Griffin, M.J., \& Read, J.P. (2012). Prospective effects of method of coercion in sexual victimization across the first college year. Journal of Interpersonal Violence, 27(12), 2503-2524.

Hathaway, L.M., Boals, A., \& Banks, J.B. (2010). PTSD symptoms and dominant emotional response to a traumatic event: An examination of DSM-IV Criterion A2. Anxiety, Stress \& Coping, 23(1), 119-126).

Kaysen, D.L., Lindgren, K.P., Lee, C.M., Lewis, M.A., Fossos, N., \& Atkins, D.C. (2010). Alcohol-involved assault and the course of PTSD in female crime victims. Journal of Traumatic Stress, 23(4), 523-527. http://doi.org/10.1002/jts.

Kessler, R.C., Sonnega, A., Bromet, E., Hughes, M., \& Nelson, C.B. (1995). Posttraumatic stress disorder in the National Comorbidity Survey. Archives of General Psychiatry, 52(12), $1048-1060$.

Kilpatrick, D.G., \& Acierno, R. (2003). Mental health needs of crime victims: Epidemiology and outcomes. Journal of Traumatic Stress, 16(2), 119-132.

Kline, R.B. (1998). Principles and practice of structural equation modeling. New York: The Guilford Press.

Koss, M.P., Gidycz, C.A., \& Wisniewski, N. (1987). The scope of rape: Incidence and prevalence of sexual aggression and victimization in a national sample of higher education students. Journal of Consulting and Clinical Psychology, 55(2), 162-170.

Krebs, C.P., Lindquist, C.H., Warner, T.D., Fisher, B.S., \& Martin, S.L. (2009). College women's experiences with physically forced, alcohol-or other drug-enabled, and drugfacilitated sexual assault before and since entering college. Journal of American College Health, 57(6), 639-649.

Lawyer, S., Resnick, H., Bakanic, V., \& Burkett, T. (2010). Forcible, drug-facilitated, and incapacitated rape and sexual assault among undergraduate women. Journal of American College Health, 58(5), 453-460. 
Layman, M.J., Gidycz, C.A., \& Lynn, S.J. (1996). Unacknowledged versus acknowledged rape victims: Situational factors and posttraumatic stress. Journal of Abnormal Psychology, 105(1), 124-131.

Littleton, H.L., Grills-Taquechel, A., \& Axsom, D. (2009). Impaired and incapacitated rape victims: Assault characteristics and post-assault experiences. Violence and Victims, 24(4), 439-457. http://doi.org/10.1891/0886-6708.24.4.439

Littleton, H.L., Rhatigan, D.L., \& Axsom, D. (2007). Unacknowledged rape: How much do we know about the hidden rape victim? Journal of Aggression, Maltreatment, \& Trauma, 14(4), 57-74.

Mohler-Kuo, M., Dowdall, G.W., Koss, M.P., \& Wechsler, H. (2004). Correlates of rape while intoxicated in a national sample of college women. Journal of Studies on Alcohol, 65(1), $37-45$.

Nishith, P., Mechanic, M.B., \& Resick, P.A. (2000). Prior interpersonal trauma: The contribution to current PTSD symptoms in female rape victims. Journal of Abnormal Psychology, 109(1), 20-25.

Peter-Hagene, L.C., \& Ullman, S. E. (2014). Sexual assault-characteristics effects on PTSD and psychosocial mediators : A cluster-analysis approach to sexual assault types. Psychological Trauma: Theory, Research, Practice, and Policy, 7(2), 162-170.

Resick, P.A. (1993). The psychological impact of rape. Journal of Interpersonal Violence, 8(2), 223-255.

Rizvi, S.L., Kaysen, D., Gutner, C.A., Griffin, M.G., \& Resick, P.A. (2008). Beyond fear: The role of peritraumatic responses in posttraumatic stress and depressive symptoms among female crime victims. Journal of Interpersonal Violence, 23(6), 853-868.

Söderlund, H., Grady, C. L., Easdon, C., \& Tulving, E. (2007). Acute effects of alcohol on neural correlates of episodic memory encoding. Neuroimage, 35(2), 928-939.

Stein, M.B., Jang, K.L., Taylor, S., Vernon, P.A., \& Livesley, W.J. (2014). Genetic and environmental influences on trauma exposure and posttraumatic stress disorder symptoms: A twin study. The American Journal of Psychiatry, 159(10), 1675-1681.

U.S. Department of Justice. (2012). Revised rape definition announced for Uniform Crime Reporting program [Press release]. Retrieved from 
http://www.fbi.gov/news/news_blog/revised-rape-definition-approved-for-uniformcrime-reporting-program

U.S. Department of Justice. (2014). Rape and sexual assault victimization among college-age females, 1995-2013. (Report No. NCJ 248471). Retrieved from http://www.bjs.gov/content/pub/pdf/rsavcaf9513.pdf

Ullman, S.E., \& Najdowski, C.J. (2010). Understanding alcohol-related sexual assaults: characteristics and consequences. Violence and Victims, 25(1), 29-44.

Ullman, S.E., Filipas, H.H., Townsend, S.M., \& Starzynski, L.L. (2007). Psychosocial correlates of PTSD symptom severity in sexual assault survivors. Journal of Traumatic Stress, 20(5), 821-831.

Walsh, K., Messman-Moore, T., Zerubavel, N., Chandley, R.B., Denardi, K.A., \& Walker, D.P. (2013). Perceived sexual control, sex-related alcohol expectancies and behavior predict substance-related sexual revictimization. Child Abuse \& Neglect, 37(5), 353-9. http://doi.org/10.1016/j.chiabu.2012.11.009

Weathers, F.W., Litz, B.T., Herman, D., Huska, J., \& Keane, T. (1994). The PTSD checklistcivilian version (PCL-C). Boston, MA: National Center for PTSD.

White, A.M. (2003). What happened? Alcohol, memory blackouts, and the brain. Alcohol Research and Health, 27(2), 186-196.

Zinzow, H.M., Resnick, H.S., Amstadter, A.B., McCauley, J.L., Ruggiero, K.J., \& Kilpatrick, D. G. (2010). Drug- or alcohol-facilitated, incapacitated, and forcible rape in relationship to mental health among a national sample of women. Journal of Interpersonal Violence, 25(12), 2217-36. http://doi.org/10.1177/0886260509354887

Zinzow, H.M., Resnick, H.S., McCauley, J.L., Amstadter, A.B., Ruggiero, K.J., \& Kilpatrick, D. G. (2012). Prevalence and risk of psychiatric disorders as a function of variant rape histories: Results from a national survey of women. Social Psychiatry and Psychiatric Epidemiology, 47(6), 893-902. http://doi.org/10.1007/s00127-011-0397-1 
Table 1

Bivariate Correlations among Study Variables

\begin{tabular}{|c|c|c|c|c|c|c|c|c|c|c|c|c|c|}
\hline Measure & 1 & 2 & 3 & 4 & 5 & 6 & 7 & 8 & 9 & 10 & 11 & 12 & 13 \\
\hline 1. Age & -- & & & & & & & & & & & & \\
\hline 2. Income & -.06 & -- & & & & & & & & & & & \\
\hline $\begin{array}{l}\text { 3. Race: African } \\
\text { American }\end{array}$ & -.06 & -.13 & -- & & & & & & & & & & \\
\hline 4. Race: Caucasian & $.17 *$ & .07 & $-.78 * *$ & -- & & & & & & & & & \\
\hline 5. Student status & $-.24 * *$ & $.17 *$ & $.24 * *$ & $-.22 * *$ & -- & & & & & & & & \\
\hline 6. Time since assault & $.43 * *$ & .02 & -.01 & .04 & -.03 & -- & & & & & & & \\
\hline 7. Peritraumatic fear & .03 & $-.20 *$ & .07 & -.13 & -.07 & .06 & -- & & & & & & \\
\hline 8. Peritraumatic injury & .07 & $-.19 *$ & -.10 & .05 & -.06 & $.17^{*}$ & $.48 * *$ & -- & & & & & \\
\hline 9. Acknowledgment & .07 & $-.18 *$ & .04 & -.06 & -.01 & .11 & $.58 * *$ & $.46^{* *}$ & -- & & & & \\
\hline 10. Self-blame & -.12 & .07 & -.01 & -.05 & .01 & -.04 & -.15 & .03 & -.04 & -- & & & \\
\hline $\begin{array}{l}\text { 11. Re-experiencing } \\
\text { symptoms }\end{array}$ & .03 & $-.23 * *$ & -.01 & -.01 & -.01 & -.04 & $.33 * *$ & $.31 * *$ & $.23 * *$ & .04 & -- & & \\
\hline $\begin{array}{l}\text { 12. Avoidance/numbing } \\
\text { symptoms }\end{array}$ & -.15 & $-.20 *$ & .10 & -.12 & .01 & -.05 & $.23 * *$ & $.23 * *$ & $.22 * *$ & .04 & $.74 * *$ & -- & \\
\hline $\begin{array}{l}\text { 13. Hyperarousal } \\
\text { symptoms }\end{array}$ & -.14 & $-.17 *$ & .10 & -.05 & .01 & -.02 & $.27 * *$ & $.21 * *$ & $.30 * *$ & .10 & $.73^{* *}$ & $.79 * *$ & -- \\
\hline $\begin{array}{l}\text { 14. Total PTSD } \\
\text { symptoms }\end{array}$ & -.10 & $-.21 * *$ & .07 & -.07 & .003 & -.03 & $.30 * *$ & $.26^{* *}$ & $.27 * *$ & .07 & $.89^{* *}$ & $.93^{* *}$ & $.92 * *$ \\
\hline
\end{tabular}

$* \mathrm{p}<.05 * * \mathrm{p}<.01$ 
Table 2

Differences in Mean PCL-C Scores by Rape Type

\begin{tabular}{|c|c|c|c|c|c|c|c|c|}
\hline & \multicolumn{2}{|c|}{$\begin{array}{l}\text { Forcible-only } \\
(\mathrm{n}=48)\end{array}$} & \multicolumn{2}{|c|}{$\begin{array}{l}\text { Combined } \\
(\mathrm{n}=29)\end{array}$} & \multicolumn{2}{|l|}{$\begin{array}{l}\text { Impaired } \\
(\mathrm{n}=56)\end{array}$} & \multicolumn{2}{|c|}{$\begin{array}{l}\text { Incapacitated } \\
(\mathrm{n}=28)\end{array}$} \\
\hline & $M$ & $S D$ & $M$ & $S D$ & $M$ & $S D$ & $M$ & $S D$ \\
\hline $\begin{array}{l}\text { Re-experiencing } \\
\text { symptoms }\end{array}$ & $11.28^{\mathrm{a}}$ & 4.74 & $14.30^{\mathrm{b}}$ & 4.84 & $10.51^{\mathrm{a}}$ & 4.66 & $12.20^{\mathrm{ab}}$ & 5.59 \\
\hline $\begin{array}{l}\text { Avoidance \& } \\
\text { Numbing } \\
\text { symptoms }\end{array}$ & $15.05^{\mathrm{ab}}$ & 6.31 & $18.34^{\mathrm{a}}$ & 6.90 & $14.03^{b}$ & 6.23 & $15.48^{\mathrm{ab}}$ & 5.94 \\
\hline $\begin{array}{l}\text { Hyperarousal } \\
\text { symptoms }\end{array}$ & $10.96^{\mathrm{a}}$ & 5.25 & $14.98^{b}$ & 5.41 & $10.28^{\mathrm{a}}$ & 5.23 & $12.83^{\mathrm{ab}}$ & 4.83 \\
\hline $\begin{array}{l}\text { Total PTSD } \\
\text { symptoms }\end{array}$ & $37.30^{\mathrm{a}}$ & 14.92 & $47.62^{\mathrm{b}}$ & 15.64 & $34.93^{\mathrm{a}}$ & 14.84 & $40.52^{\mathrm{ab}}$ & 14.38 \\
\hline
\end{tabular}

Note. Within each row, means that do not share superscripts are significantly different at $\mathrm{p}<.05$, Bonferroni-corrected. 
Table 3

Differences in Acknowledgment, Self-blame, and Peritraumatic Injury by Rape Type

\begin{tabular}{|c|c|c|c|c|c|c|c|c|}
\hline & \multicolumn{2}{|c|}{$\begin{array}{l}\text { Forcible-only } \\
(\mathrm{n}=48)\end{array}$} & \multicolumn{2}{|c|}{$\begin{array}{l}\text { Combined } \\
(\mathrm{n}=29)\end{array}$} & \multicolumn{2}{|c|}{$\begin{array}{l}\text { Impaired } \\
(\mathrm{n}=56)\end{array}$} & \multicolumn{2}{|c|}{$\begin{array}{l}\text { Incapacitated } \\
(\mathrm{n}=28)\end{array}$} \\
\hline & $M$ & $S D$ & $M$ & $S D$ & $M$ & $S D$ & $M$ & $S D$ \\
\hline Acknowledgment & $4.63^{\mathrm{a}}$ & 2.09 & $5.17^{\mathrm{a}}$ & 1.97 & $2.63^{b}$ & 1.75 & $4.21^{\mathrm{a}}$ & 2.20 \\
\hline Self-blame & 2.75 & 1.26 & 3.07 & 1.13 & 3.14 & 1.14 & 3.36 & 1.42 \\
\hline $\begin{array}{l}\text { Peritraumatic } \\
\text { Injury }\end{array}$ & $2.46^{\mathrm{ac}}$ & 1.11 & $3.07^{\mathrm{c}}$ & 1.25 & $1.61^{\mathrm{bd}}$ & 0.93 & $2.25^{\mathrm{ad}}$ & 1.17 \\
\hline
\end{tabular}

Note. Within each row, means that do not share superscripts are significantly different at $\mathrm{p}<.05$, Bonferroni-corrected. 


\section{Figure 1.}

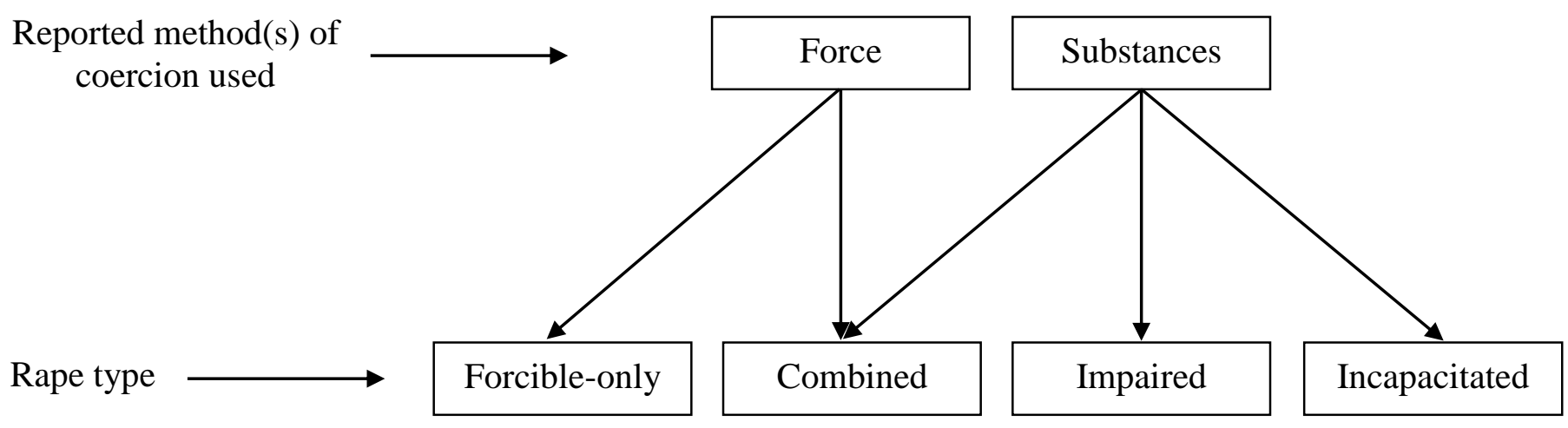

Conceptualization of rape type for the current study. The prototypical "forcible" and "substanceinvolved" groups are broken down into four distinct groups, defined by the relative use of force and substances as a method of coercion used by the perpetrator. 
Figure 2.

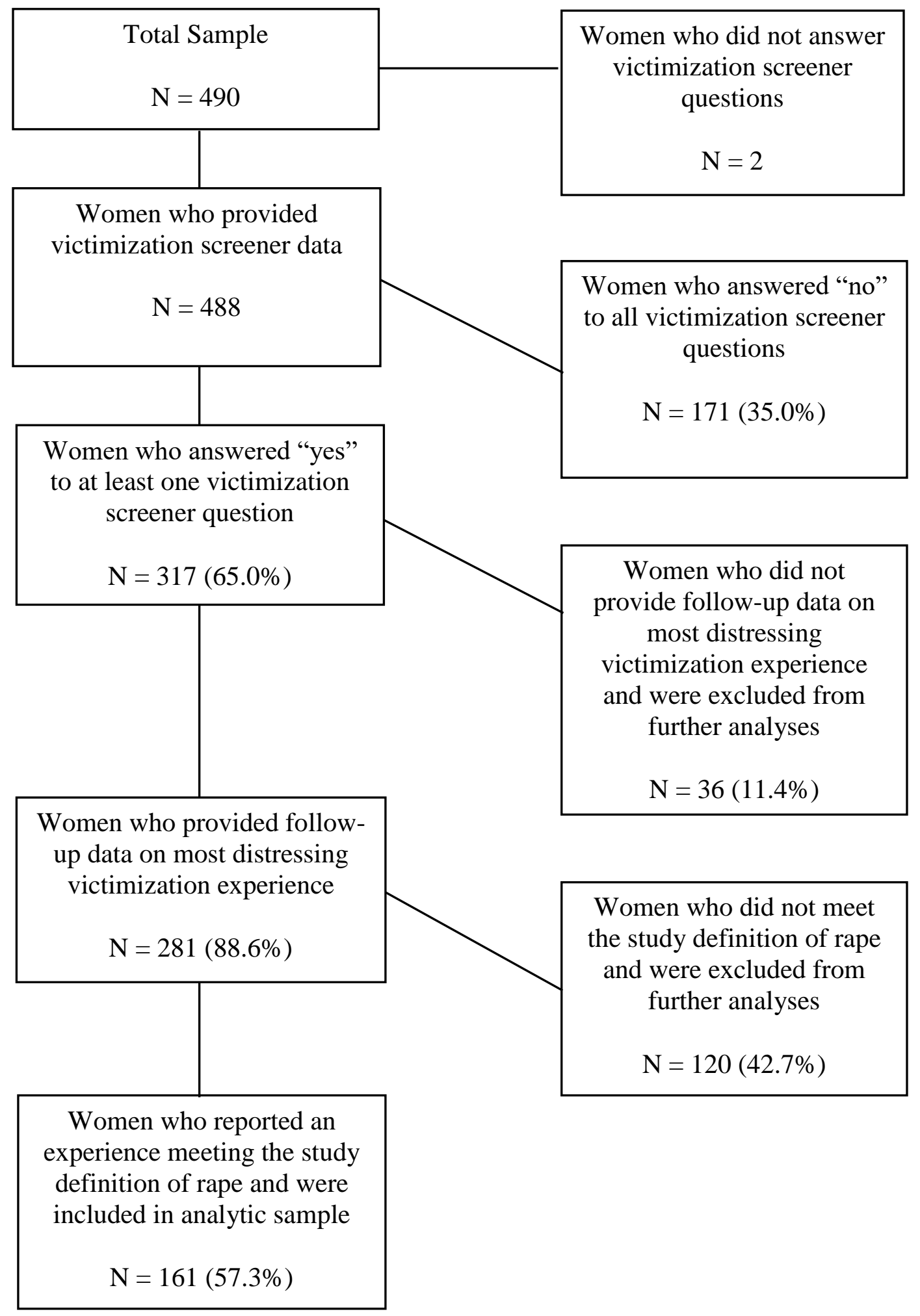

Breakdown of participant selection for the current study. The analytic sample consisted of 161 participants. 


\section{Figure 3.}

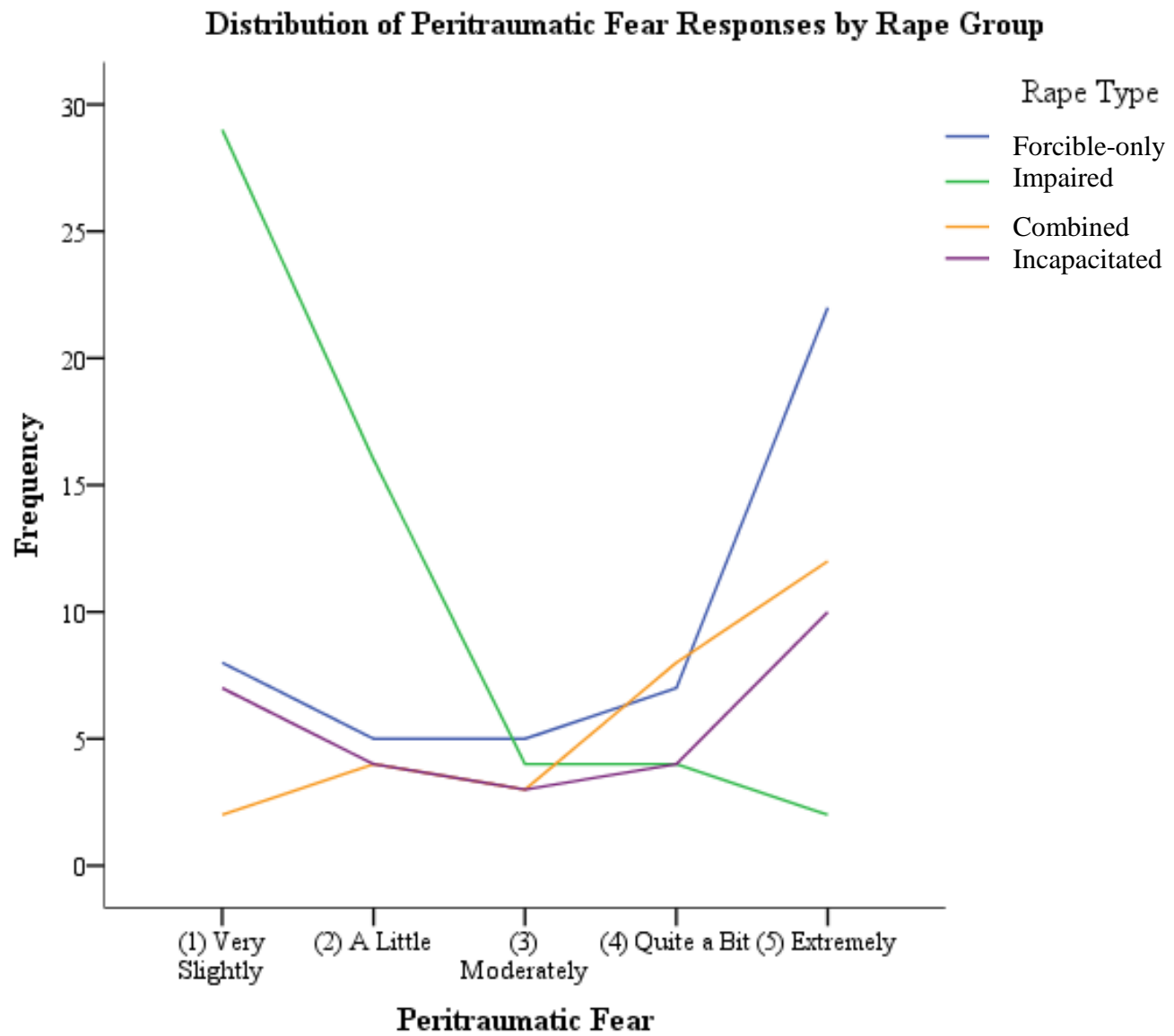

Distribution of peritraumatic fear responses by rape type. Results of post-hoc analyses following the Kruskal-Wallis test reveal that the distribution for the impaired group (green) is significantly different than those of the other groups. 